Gut, 1973, 14, 895-902

\title{
Cholic acid synthesis as an index of the severity of liver disease in man
}

\author{
WILLIAM C. McCORMICK III ${ }^{1}$, C. COOPER BELL, Jr, LEON SWELL, AND \\ Z. RENO VLAHCEVIC \\ From the Department of Medicine (Division of Gastroenterology), Veterans Administration Hospital, and \\ Departments of Medicine, Surgery, and Biochemistry, Virginia Commonwealth University, \\ Health Sciences Division, Richmond, Virginia 23249 USA
}

SUMMARY Bile acid pool size and kinetics were determined in 17 patients with cirrhosis and 11 patients without liver disease and correlated with the severity of liver disease as determined by the usual clinical and laboratory criteria. In order to assess the severity of liver disease, a grading system was devised which assigned numerical values to various clinical signs and laboratory results. The total clinical score and the patients were divided into two groups of advanced (7-18 points) or mild (1-6 points) cirrhosis. The clinical rating was then correlated with the various aspects of bile acid metabolism. Cholic acid synthesis was markedly reduced in the early stages of cirrhosis and continued to decrease with the advancement of the liver disease. There was an inverse correlation between synthesis of cholic acid and the severity of cirrhosis. Nine of the 10 patients with advanced cirrhosis and a very low cholic acid synthetic rate (average $68 \mathrm{mg}$ per day) died within one to 13 months from the start of the study. Patients with mild cirrhosis also had significantly reduced cholic acid synthesis (average $152 \mathrm{mg}$ per day) but they all were well and alive three to 23 months after the study. In contrast, chenodeoxycholic acid synthesis was not markedly affected in either patients with mild or advanced cirrhosis. There was also a high degree of correlation between the fractional daily turnover rate of cholic acid and the severity of liver disease. The fractional daily turnover rate of cholic acid was greatly reduced $(50 \%)$ in patients with advanced cirrhosis. Deoxycholic acid was reduced in patients with mild cirrhosis and virtually absent from the bile of patients with advanced cirrhosis. The findings of the present report provide evidence that cholic acid synthesis is a sensitive indicator of the hepatocellular damage, whereas chenodeoxycholic acid synthesis is relatively unaffected by cirrhosis. The selective alteration in cholic acid synthesis probably resides in a deficiency of one or more enzymes regulating the formation of the 3-keto, 7 alpha, 12 alpha-dihydroxy precursor of cholic acid.

A number of reports (Rudman and Kendall, 1957; Vlahcevic, Buhac, Bell, and Swell, 1970) have presented evidence that marked alterations in the metabolism of bile acids are present in patients with acute and chronic liver disease. Patients with liver disease have been shown to have elevated serum bile acids (Rudman and Kendall, 1957; Osborn, Wootton, Da Silva, and Sherlock, 1959), a reversal of the plasma trihydroxy to dihydroxy bile acid ratio (Carey, 1958), a decreased removal and conjugation of bile acids from the plasma (Blum and Spritz,

${ }^{1}$ Deceased.

Received for publication 15 August 1973.
1966; Theodor, Spritz, and Sleisenger, 1968), a diminished enterohepatic bile acid pool (Vlahcevic, Buhac, Farrar, Bell, and Swell, 1971), a marked reduction in cholic acid synthesis (Vlahcevic et al, 1971; Vlahcevic, Juttijudata, Bell, and Swell, 1972), and a very low percentage of biliary deoxycholic acid (Vlahcevic et al, 1970). These abnormalities in bile acid metabolism can probably be attributed to a combination of parenchymal liver cell disease and the presence of portasystemic shunts.

Carey (1958) reported that patients with cirrhosis had a relative increase in plasma dihydroxy bile acids which resulted in a decrease in the ratio of trihydroxy to dihydroxy bile acids. Diagnostic and 
prognostic significance was attached to the persistence of this altered ratio. It was also suggested that these differences in patients with cirrhosis might be accounted for on the basis that cholic acid synthesis was affected to a greater extent than chenodeoxycholic acid synthesis. Recently it has been demonstrated (Vlahcevic et al, 1972) that patients with cirrhosis do indeed have a marked impairment in the synthesis of cholic acid. Patients with liver disease were found to synthesize only about one-third the amount of cholic acid per day as that synthesized by normal subjects. On the other hand, chenodeoxycholic acid synthesis was virtually unaffected in cirrhotic patients. This selective alteration in the synthesis of cholic acid may result from a deficiency of one or more enzymes regulating the conversion of cholesterol to the 3-keto, 7 alpha, 12 alpha-dihydroxy cholic acid intermediate which is an immediate precursor of cholic acid. This blockage could reside in the 12 alpha-hydroxylating step since chenodeoxycholic acid synthesis is minimally affected. A deficiency of the 12 alpha-hydroxylase enzyme would lead to a selective impairment of cholic acid synthesis and could explain the decrease in the ratio of plasma trihydroxy to dihydroxy bile acids. In the course of the earlier study (Vlahcevic et al, 1972) on bile acid metabolism in cirrhosis there appeared to be a relationship between the severity of liver disease and the synthesis of cholic acid. The purpose of the present study was to provide information on a possible relationship between cholic and chenodeoxycholic acid synthesis and the degree and prognosis of liver disease as determined by the usual clinical and laboratory criteria.

\section{Materials and Methods}

\section{PATIENTS}

Eleven male subjects without and 17 male subjects with cirrhosis ( 35 to 67 years) were studied. The control subjects had no clinical or laboratory evidence of liver disease. Their liver function tests (serum albumin, bilirubin, alkaline phosphatase, serum glutamic oxaloacetic transaminase) were all within normal limits. The clinical diagnosis, bile acid pools, and related kinetic data of the patients without liver disease have been reported in a previous study (Vlahcevic, Miller, Farrar, and Swell, 1971). The diagnosis of cirrhosis was made by the usual clinical and laboratory criteria and confirmed in 15 of the 17 patients with cirrhosis by percutaneous liver biopsy, at surgery for a portacaval shunt, or at necropsy. The aetiology of cirrhosis in all patients was associated with an excessive alcohol intake. Patients with acute fatty liver or acute alcoholic hepatitis were not included in the study. The pertinent clinical and laboratory information on the liver disease patients is presented in table I. One of us (W.C.McC.) evaluated patients and their hospital records without prior knowledge of the bile acid synthesis and pool data. The physical findings, laboratory results, radiological and endoscopic examination, liver biopsy slides, and other pertinent information were examined and tabulated. In order to assess the severity of the liver disease a grading system was devised which assigned numerical values to clinical and laboratory phenomena associated with the disease as shown in table II. The major complications of cirrhosis such as ascites, varices,

\begin{tabular}{|c|c|c|c|c|c|c|c|c|}
\hline Patient No. ${ }^{1}$ & Age $(y r)$ & $\begin{array}{l}\text { Histological } \\
\text { Diagnosis }\end{array}$ & Ascites & Varices & $\begin{array}{l}\text { Hepatic } \\
\text { Coma }\end{array}$ & Albumin $(\mathrm{g} \%)$ & $\begin{array}{l}\text { Clinical } \\
\text { Score }\end{array}$ & Survival (mth) \\
\hline \multicolumn{9}{|c|}{ Mild Cirrhosis (Score 1-6) } \\
\hline 1 & 49 & Cirrhosis & No & No & No & $3 \cdot 1$ & 1 & 23 Living \\
\hline 2 & 53 & Cirrhosis & No & No & No & $3 \cdot 9$ & 1 & 21 Living \\
\hline 3 & 52 & Cirrhosis & Yes & No & No & $3 \cdot 6$ & 2 & 21 Living \\
\hline 4 & 58 & Cirrhosis & Yes & No & No & 3.9 & 2 & 22 Living \\
\hline 5 & 41 & Cirrhosis & No & No & No & $4 \cdot 3$ & 3 & 3 Living ${ }^{2}$ \\
\hline 6 & 35 & Cirrhosis & Yes & No & No & $2 \cdot 0$ & 3 & 23 Living \\
\hline 7 & 43 & Cirrhosis & Yes & No & No & $4 \cdot 0$ & 3 & 23 Living \\
\hline \multicolumn{9}{|c|}{ Advanced Cirrhosis (Score 7-18) } \\
\hline 8 & 48 & Cirrhosis & Yes & No & Yes & $2 \cdot 7$ & 10 & 12 Deceased \\
\hline 9 & 62 & Not obtained & Yes & Yes & No & $2 \cdot 0$ & 10 & 5 Deceased \\
\hline 10 & 44 & Cirrhosis & Yes & Yes & No & $3 \cdot 6$ & 10 & 7 Deceased \\
\hline 11 & 47 & Cirrhosis & Yes & Yes & Yes & $2 \cdot 8$ & 12 & 7 Living ${ }^{2}$ \\
\hline 12 & 50 & Not obtained & Yes & Yes & Yes & $1 \cdot 8$ & 12 & 5 Deceased \\
\hline 15 & 67 & Cirrhosis & Yes & Yes & Yes & $1 \cdot 8$ & 14 & 1 Deceased \\
\hline 16 & 42 & Cirrhosis & Yes & Yes & Yes & $1 \cdot 3$ & 15 & 3 Deceased \\
\hline 17 & 49 & Cirrhosis & Yes & Yes & Yes & $2 \cdot 0$ & 18 & 2 Deceased \\
\hline
\end{tabular}

Table I Pertinent clinical information on patients with cirrhosis

${ }^{1}$ All patients were males.

'The bile acid pools and kinetics on these two patients were carried out 18 months after the other patients were studied. 


\begin{tabular}{|c|c|}
\hline Clinical Signs & Grade Points \\
\hline $\begin{array}{l}\text { Ascites } \\
\text { Intractable (not responding to intensive diuretic } \\
\text { therapy) } \\
\text { Large ascites (requiring intensive therapy in } \\
\text { hospital) } \\
\text { Mild ascites (not requiring therapy in hospital) }\end{array}$ & $\begin{array}{l}2 \\
1\end{array}$ \\
\hline $\begin{array}{l}\text { Hydrothorax } \\
\text { Associated with ascites }\end{array}$ & 1 \\
\hline $\begin{array}{l}\text { Varices } \\
\text { Documented bleeding from oesophageal varices } \\
\text { (by endoscopy) or portacaval shunt for bleeding } \\
\text { No bleeding, but varices documented either by } \\
\text { oesophagoscopy or radiologically }\end{array}$ & $\begin{array}{l}3 \\
2\end{array}$ \\
\hline Hepatosplenomegaly & 1 \\
\hline Collateral abdominal veins & 1 \\
\hline $\begin{array}{l}\text { Hepatic coma } \\
\text { Severe and/or recurrent coma } \\
\text { A single episode of coma or precoma }\end{array}$ & $\begin{array}{l}3 \\
2\end{array}$ \\
\hline $\begin{array}{l}\text { Prothrombin concentration } \\
0-29 \% \\
30-49 \% \\
50-80 \%\end{array}$ & $\begin{array}{l}3 \\
2 \\
1\end{array}$ \\
\hline $\begin{array}{l}\text { Albumin } \\
\text { Less than } 1.4 \mathrm{~g} \\
1.5-2.4 \mathrm{~g} \\
2.5-3.4 \mathrm{~g}\end{array}$ & $\begin{array}{l}3 \\
2 \\
1\end{array}$ \\
\hline $\begin{array}{l}\text { Malnutrition } \\
\text { Severe cachexia } \\
\text { Moderate cachexia } \\
\text { Mild cachexia }\end{array}$ & $\begin{array}{l}3 \\
2 \\
1\end{array}$ \\
\hline
\end{tabular}

Table II Clinical grading system

hepatic coma, malnutrition, and laboratory function tests (albumin and prothrombin times) were graded on a scale from 1 to 3 points. For exa mple, intractable ascites was defined as rapidly accumulating ascites which did not respond to intensive diuretic therapy, thereby requiring continuous use of diuretics. This was a major cause for hospital admission on numerous occasions. Ascites of this type was rated 3 points. Intensive diuretic therapy was defined as a combination of furosemide (Lasix, Hoechst Pharmaceuticals) or edecrinic acid (Edecrin, Merck Sharp \& Dohme) with spironolactone (Aldactone, Searle) coupled with a low salt diet and fluid restriction. Moderate ascites was defined as large ascites responding promptly to the same diuretic regimen, but requiring intensive therapy in the hospital ( 2 points). Patients with mild ascites did not usually require diuretic therapy and the ascites was resolved by spontaneous diuresis on bed rest and salt restriction (1 point). The grading system also differentiated severe, protracted, or recurrent coma ( 3 points) from transient episodes of coma or precoma ( 2 points). Documented variceal bleeding was given more points (3) than the presence of varices without bleed- ing ( 2 points). The diagnosis of varices was made by barium swallow and/or oesophagoscopy. The clinical stigmata of chronic liver disease such as hepatosplenomegaly and collateral abdominal veins were given 1 point. The severity of malnutrition was estimated on the basis of the lean body mass and graded on a scale of severe cachexia (3 points), moderate ( 2 points), and mild (1 point). Bilirubin, SGOT, and SGPT were not used in computing the clinical score since these liver function tests reflect the activity rather than the advancement of liver disease. Two liver function tests (albumin and prothrombin time) were selected because they more closely reflect the severity and chronicity of liver disease. A total clinical score was derived from the grading system, and the patients were divided into two categories, ie, advanced cirrhosis (7-18 points) and mild cirrhosis (1-6 points) (table I). Patients with advanced cirrhosis were defined as those who had at least two of the six following clinical and/or laboratory complications of cirrhosis: ascites, hepatic coma, varices (or portacaval shunt), markedly decreased lean body mass, albumin less than $2.5 \mathrm{~g}$, and prothrombin concentration less than $40 \%$. Patients classified as having mild cirrhosis were those who had a histological diagnosis of cirrhosis, but there was no evidence of any major clinical or laboratory complication from their liver disease such as protracted ascites, hepatic coma, or variceal bleeding at the time of the study or in the past. All patients in the study were followed on a regular basis in order to determine whether the classification actually was representative of the patient's clinical condition. With the exception of one patient (patient 11) who had only a seven-month follow up after the study, all patients classified as having advanced cirrhosis died within one to 13 months. In contrast, all patients classified as having mild cirrhosis are still alive (average 22 months) and are doing well. This correlation supports the validity of our clinical grading system in terms of both the advancement of liver disease and prognosis. Patients classified as having advanced cirrhosis died from bleeding oesophageal varices (patients $9,10,16$, and 17) and peritonitis with Gram-negative septicaemia (patients 14 and 15 ). Patients 12 and 13 died with respiratory arrest possibly secondary to aspiration. In addition, all patients in this group terminally lapsed into hepatic coma and developed renal failure of cirrhosis. Patient 8 had chronic hepatic encephalopathy requiring continuous hospitalization manifested with bizarre behaviour, episodes of frequent hepatic precoma, and sensitivity to dietary protein in excess of 30 to $40 \mathrm{~g}$. He died of aspiration pneumonia in another hospital. Patients 13, 14, and 16 had portacaval shunt surgery before the study. Patient 14 
was not ingesting alcohol but still required numerous admissions to hospital for recurrent hepatic encephalopathy. Because of the advanced liver disease and marked alteration of liver function tests, none of the patients with bleeding varices in the group of advanced cirrhosis were candidates for a portacaval shunt.

The patients were hospitalized on a metabolic ward and fed a standard 2500 calorie diet for four days before the study. Drugs were discontinued before the study. None of the patients had diarrhoea or constipation during the experiment. After four days on the diet each patient received orally $15 \mu \mathrm{c}$ of ${ }^{14} \mathrm{C}$-cholic acid and $15 \mu \mathrm{c}$ of ${ }^{14} \mathrm{C}$-chenodeoxycholic acid as the sodium salts. Bile-rich duodenal fluid was obtained by intubation with a Dreiling doublelumen tube at daily intervals for at least four days and in some patients for periods up to seven days. Bile flow was stimulated by the intravenous injection of 0.75 Ivy units of cholecystokinin per $\mathrm{kg}$ of body weight. (Cholecystokinin was obtained from Professor Jorpes, Karolinska Institutet, Stockholm, Sweden.) A small portion of the bile-rich duodenal fluid $(5 \mathrm{ml})$ was used for analysis. The remainder of the bile was returned to the patient via the Dreiling tube.

\section{METHODS}

The bile-rich duodenal fluid obtained from these patients was immediately immersed in an ice bath and extracted with 20 volumes of 2:1 chloroform: methanol and partitioned with 0.2 volume of water (Folch, Lees, and Stanley, 1957). Bile acid analysis was carried out on the upper methanolwater phase as described earlier (Vlahcevic et al, 1971; Swell, 1968). Bile acid rate constants, synthesis, and pools were calculated from the cholic and chenodeoxycholic acid specific activity decay curves and the amount of administered ${ }^{14} \mathrm{C}$-bile acids as described earlier (Vlahcevic et al, 1972; Vlahcevic et al, 1971).

Cholic and chenodeoxycholic acid synthesis and fractional daily turnover rates were correlated by simple regression analysis (Snedecor, 1956) with the severity of liver disease (clinical rating). The group $t$ test was used to test for the level of significance between the groups (Snedecor, 1956). All calculations as well as statistical analysis were carried out by an IBM 370 computer.

\section{Results}

The synthesis of the primary bile acids in patients with and without cirrhosis is shown in table III. Patients with mild cirrhosis had a highly significant decrease in the synthesis of cholic acid when compared

\begin{tabular}{|c|c|c|c|}
\hline \multirow[t]{2}{*}{ Patient No. } & \multicolumn{3}{|c|}{ Bile Acid Synthesis (mg per day) } \\
\hline & Cholic Acid & $\begin{array}{l}\text { Chenodeoxycholic } \\
\text { Acid }\end{array}$ & $\begin{array}{l}\text { Cholic/Cheno } \\
\text { deoxycholic Acid }\end{array}$ \\
\hline $\begin{array}{l}\text { No Cirrhosis } \\
\text { Mean (11) }\end{array}$ & $345 \cdot 1 \pm 147 \cdot 2$ & $169 \cdot 2 \pm 58 \cdot 0$ & $2.08 \pm 0.67$ \\
\hline $\begin{array}{l}\text { Mild Cirrhosi } \\
1 \\
2 \\
3 \\
4 \\
5 \\
6 \\
7\end{array}$ & $\begin{array}{r}\text { is } \\
117 \\
190 \\
91 \\
268 \\
112 \\
120 \\
166\end{array}$ & $\begin{array}{r}105 \\
212 \\
85 \\
150 \\
136 \\
111 \\
113\end{array}$ & $\begin{array}{l}1 \cdot 11 \\
0.90 \\
1.07 \\
1 \cdot 79 \\
0.82 \\
1.08 \\
1.47\end{array}$ \\
\hline Mean & $\begin{array}{l}152 \pm 62 \\
P<0.01\end{array}$ & $\begin{array}{l}130 \pm 42 \\
P>0.05 \mathrm{NS}^{1}\end{array}$ & $\begin{array}{l}1 \cdot 18 \pm 0.34 \\
P<0.01\end{array}$ \\
\hline $\begin{array}{l}\text { Advanced Cir } \\
8 \\
9 \\
10 \\
11 \\
12 \\
13 \\
14 \\
15 \\
16 \\
17\end{array}$ & $\begin{array}{l}\text { rhosis } \\
.110 \\
100 \\
156 \\
47 \\
37 \\
28 \\
72 \\
18 \\
49 \\
61\end{array}$ & $\begin{array}{r}150 \\
172 \\
114 \\
113 \\
63 \\
59 \\
132 \\
120 \\
160 \\
90\end{array}$ & $\begin{array}{l}0.73 \\
0.58 \\
1.37 \\
0.42 \\
0.59 \\
0.48 \\
0.55 \\
0.15 \\
0.31 \\
0.68\end{array}$ \\
\hline Mild versus & $\begin{array}{l}68 \pm 42 \\
P<0.001\end{array}$ & $\begin{array}{l}117 \pm 38 \\
P<0.05\end{array}$ & $\begin{array}{l}0.58 \pm 0.33 \\
P<0.001\end{array}$ \\
\hline advanced & $P<0.001$ & $\mathrm{P}>0.05 \mathrm{NS}^{1}$ & $P<0.01$ \\
\hline
\end{tabular}

Table III Synthesis of primary bile acids NS $=$ not significant.

with the group with no cirrhosis. Patients with advanced cirrhosis had an even more marked decrease in cholic acid synthesis. These patients synthesized on an average of only $68 \mathrm{mg}$ cholic acid per day which was $80 \%$ less than the group without cirrhosis. Also, patients with advanced cirrhosis synthesized significantly less cholic acid than patients with mild cirrhosis. In contrast to cholic acid synthesis, chenodeoxycholic acid production was minimally affected in cirrhotic patients. Patients with mild cirrhosis had a $23 \%$ reduction in chenodeoxycholic acid synthesis and patients with advanced cirrhosis had a $31 \%$ decrease in the synthesis of this bile acid. Chenodeoxycholic acid synthesis in the group of patients with mild cirrhosis was not significantly different from patients without liver disease. In patients with advanced cirrhosis the synthesis of chenodeoxycholic acid was significantly lower $(P<0.05)$ than in control subjects. However, this decrease in synthesis of chenodeoxycholic acid was of a much lesser magnitude than that of cholic acid. These alterations in cholic and chenodeoxycholic acid synthesis produced a reversal in the pattern of synthesis of primary bile acids. In the normal patient the daily synthesis of cholic acid was found to be twice that of chenodeoxycholic acid. In patients with 
mild cirrhosis the ratio dropped to 1.2 and in patients with advanced cirrhosis the ratio was 0.6 .

- Correlation of the daily synthesis of primary bile acids with the severity of liver disease as indicated by the clinical rating is shown in figure 1 . There was $a^{\prime}$ high degree of correlation $(r=0.72)$ between the

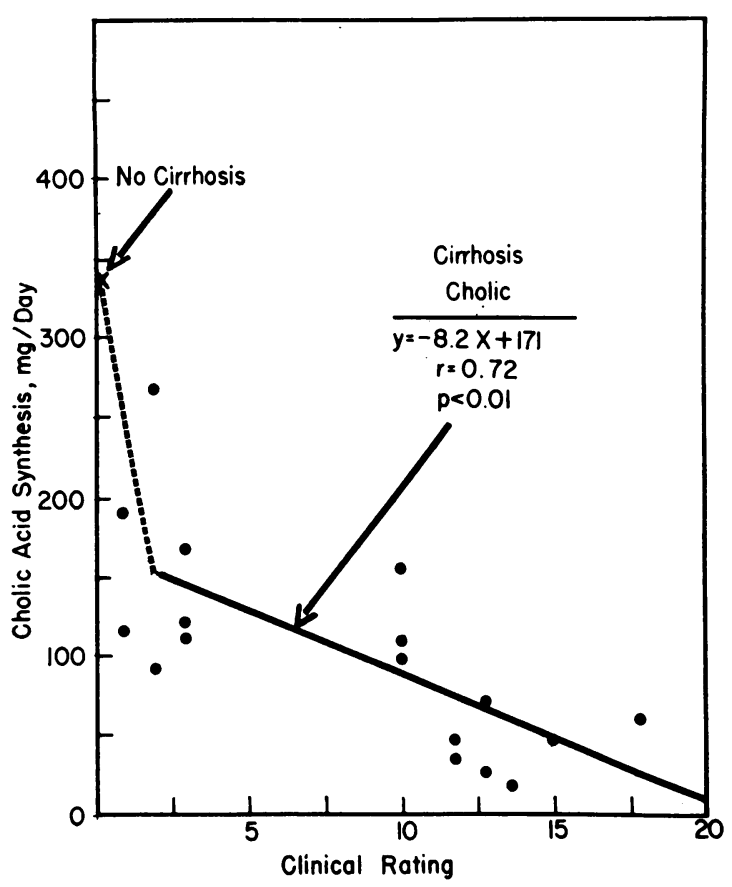

Fig 1 Correlation of the severity (clinical rating) of liver disease with bile acid synthesis. The average daily cholic acid synthesis for the group with no cirrhosis is shown on the $Y$ intercept (zero clinical rating). The first portion of the curve is from the point of no cirrhosis to the mean of the group with mild cirrhosis. severity of liver disease and the daily synthesis of cholic acid. The data suggest a dual relationship between the severity of liver disease and synthesis of cholic acid. During the very early stages of cirrhosis, which is not easily detected by the usual clinical criteria, there is a marked decrease in cholic acid synthesis as is indicated by the sharp decline from the mean value for the normal group ( $345 \mathrm{mg}$ per day) to the average daily synthesis of the mild group (152 mg per day). Following this initial decline there is a secondary negative correlation between the severity of liver disease and cholic acid synthesis. In contrast to cholic acid synthesis, chenodeoxycholic acid synthesis did not correlate with the severity of liver disease.

The bile acid pool and fractional daily turnover rate $(\mathrm{K})$ of primary bile acids is shown in table IV. Total bile acid pool was greatly reduced (about $50 \%$ ) in patients with mild and advanced cirrhosis when compared with patients without cirrhosis. These marked changes in the total bile acid pool occurred in the early stages of cirrhosis since there was no reduction in the total bile acid pool with further progression of the liver disease. There was also a highly significant decrease in the cholic acid pool in patients with mild and advanced cirrhosis when compared with the group with no cirrhosis. There were no significant differences in the cholic acid pool size between patients with mild and advanced cirrhosis. The chenodeoxycholic acid pool was significantly reduced in patients with mild cirrhosis but not in patients with advanced cirrhosis. The fractional daily turnover rate (K) of primary bile acid was not significantly altered in patients with mild cirrhosis. However, in patients with advanced cirrhosis the turnover rate of cholic acid was significantly reduced when compared with that in patients with no cirrhosis. The chenodeoxycholic acid turnover rate was reduced in patients with

\begin{tabular}{|c|c|c|c|c|c|}
\hline \multirow{2}{*}{$\begin{array}{l}\text { No. of } \\
\text { Patients }\end{array}$} & \multicolumn{2}{|l|}{ Cholic Acid } & \multicolumn{2}{|c|}{ Chenodeoxycholic Acid } & \multirow{2}{*}{$\begin{array}{l}\text { Total Bile Acid } \\
\text { Pool }(g)\end{array}$} \\
\hline & $\begin{array}{l}\text { Turnover Rate }(K) \\
\left(\text { Days }^{-1}\right)\end{array}$ & Pool (g) & $\begin{array}{l}\text { Turnover Rate (K) } \\
\left(\text { Days }^{-1}\right)\end{array}$ & Pool (g) & \\
\hline $\begin{array}{l}\text { No Cirrhosis } \\
11\end{array}$ & $0.314 \pm 0.122$ & $1 \cdot 13 \pm 0.35$ & $0.228 \pm 0.092$ & $0.82 \pm 0.16$ & $2 \cdot 33 \pm 0.47$ \\
\hline $\begin{array}{l}\text { Mild Cirrhosis } \\
7\end{array}$ & $\begin{array}{l}0.301 \pm 0.106 \\
P>0.05 \mathrm{NS}^{1}\end{array}$ & $\begin{array}{l}0.49 \pm 0.06 \\
P<0.001\end{array}$ & $\begin{array}{l}0.288 \pm 0.107 \\
P>0.05 \mathrm{NS}^{1}\end{array}$ & $\begin{array}{l}0.49 \pm 0.20 \\
P<0.01\end{array}$ & $\begin{array}{l}1.09 \pm 0.31 \\
P<0.001\end{array}$ \\
\hline $\begin{array}{l}\text { Advanced Cirrh } \\
10\end{array}$ & $\begin{array}{l}\text { osis } \\
0.144 \pm 0.068 \\
P<0.01\end{array}$ & $\begin{array}{l}0.46 \pm 0.17 \\
P<0.001\end{array}$ & $\begin{array}{l}0.184 \pm 0.064 \\
P>0.05 \mathrm{NS}^{1}\end{array}$ & $\begin{array}{l}0.67 \pm 0.25 \\
P>0.05 \mathrm{NS}^{1}\end{array}$ & $\begin{array}{l}1.17 \pm 0.36 \\
P<0.001\end{array}$ \\
\hline $\begin{array}{l}\text { Mild versus } \\
\text { advanced }\end{array}$ & $P<0.01$ & $P>0.05 \mathrm{NS}^{1}$ & $P<0.05$ & $P>0.05 \mathrm{NS}^{1}$ & $\mathrm{P}>0.05 \mathrm{NS}^{1}$ \\
\hline
\end{tabular}

Table IV Bile acid pools and turnover of primary bile acids

${ }^{1} \mathrm{NS}=$ not significant. 


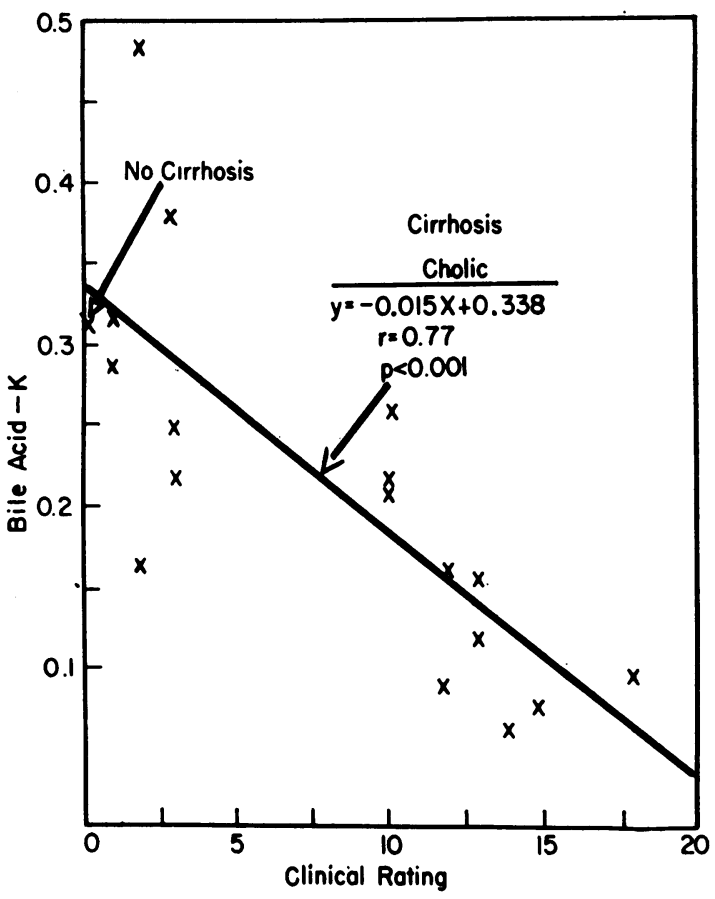

Fig 2 Correlation of primary bile acid turnover with severity' (clinical rating) of liver disease. The regression line represents the relationship between the cholic acid rate constant and the clinical rating. The average cholic acid rate constant for the group with no cirrhosis is shown on the $Y$ intercept (zero clinical rating).

advanced cirrhosis but the difference was not statistically significant.

The correlation of the cholic acid fractional daily turnover rate $(\mathbf{K})$ with the severity of liver disease is shown in figure 2 . There was significant correlation $(r=0.77)$ between the turnover rate of cholic acid and the severity of liver disease. The intercept of the regression line of this relationship was close to the average cholic acid rate constant for the group

\begin{tabular}{|c|c|c|c|c|}
\hline \multirow{2}{*}{$\begin{array}{l}\text { No. of } \\
\text { Patients }\end{array}$} & \multicolumn{4}{|c|}{ Percentage of Total Bile Acids } \\
\hline & Cholic & $\begin{array}{l}\text { Cheno- } \\
\text { deoxycholic }\end{array}$ & Deoxycholic & Lithocholic \\
\hline \multicolumn{5}{|c|}{ No Cirrhosis } \\
\hline 11 & $43 \cdot 4 \pm 8.9$ & $40 \cdot 1 \pm 6 \cdot 5$ & $14 \cdot 6 \pm 8 \cdot 3$ & $1.9 \pm 1 \cdot 1$ \\
\hline \multicolumn{5}{|c|}{ Mild Cirrhosis } \\
\hline 7 & $\begin{array}{l}45.7 \pm 10.8 \\
P>0.05 \mathrm{NS}^{1}\end{array}$ & $\begin{array}{l}45.5 \pm 7.8 \\
P>0.05 \mathrm{NS}^{1}\end{array}$ & $\begin{array}{l}7.5 \pm 4.1 \\
P<0.05\end{array}$ & $\begin{array}{l}1.3 \pm 0.7 \\
P>0.05 \mathrm{NS}^{1}\end{array}$ \\
\hline \multicolumn{5}{|c|}{ Advanced Cirrhosis } \\
\hline & $\begin{array}{l}35.3 \pm 8.0 \\
P<0.05\end{array}$ & $\begin{array}{l}61.5 \pm 8.6 \\
P<0.001\end{array}$ & $\begin{array}{l}0.9 \pm 0.5 \\
P<0.001\end{array}$ & $\begin{array}{l}2.2 \pm 1.5 \\
P>0.05 \mathrm{NS}^{1}\end{array}$ \\
\hline
\end{tabular}

Table V Bile acid composition

${ }^{1} \mathrm{NS}=$ not significant. without cirrhosis. There was also a significant relationship between the chenodeoxycholic acid turnover rate and the severity of liver disease. However, this correlation was not as good $(r=0.60)$ as for cholic acid.

The bile acid composition is shown in table V. Patients with mild cirrhosis had no significant changes in the percentage of cholic and chenodeoxycholic acid. However, there was a significant decrease in the percentage of deoxycholic acid. Patients with advanced cirrhosis had a significant decrease in the percentage of cholic acid, a highly significant increase in the percentage of chenodeoxycholic acid, and virtually no biliary deoxycholic acid.

\section{Discussion}

The results of the present and earlier reports (Vlahcevic et al, 1971; Vlahcevic et al, 1972) have shown that patients with cirrhosis have a diminished bile acid pool, a decreased turnover rate of cholic acid, and a pronounced decrease in cholic acid synthesis. Chenodeoxycholic acid synthesis, turnover rate, and pool size are affected to a much lesser extent than cholic acid. In addition, the data of the present study also show that there is a high degree of correlation between the severity of the cirrhosis and the synthesis of cholic acid. No such relationship was present for chenodeoxycholic acid. Of particular significance was the observation that cholic acid synthesis was markedly reduced even in the group of patients with mild cirrhosis. Although there was a further decrease in cholic acid synthesis as the disease advanced, the greatest decrease in the amount of cholic acid synthesized per day occurred during the early phase of liver disease. These findings suggest that significant alterations in cholic acid synthesis must occur before the onset of significant clinical symptoms. Cholic acid synthesis may therefore be a very sensitive indicator of the degree of parenchymal liver cell damage. Early changes in liver function not detectable by other clinical and laboratory procedures may perhaps be ascertained by measuring cholic acid synthesis. Since the patients of the present study had alcoholic cirrhosis, early changes in bile acid metabolism may be induced by excessive alcohol intake before any significant parenchymal liver cell damage has occurred. Of prognostic significance was the finding that all but one of the patients with a very low cholic acid synthesis died within one year from the time the study was carried out. Chenodeoxycholic acid synthesis did not correlate with survival.

The first step in the formation of bile acids from cholesterol is the hydroxylation at the 7 position to produce 7 alpha-hydroxycholesterol (Danielsson and 
Tchen, 1968; Bergstrom and Danielsson, 1968). Recent reports (Shefer, Hauser, Bekersky, and Mosbach, 1970; Shefer, Hauser, and Mosbach, 1968) indicate that the hydroxylation step is subject to feed-back control and is probably the major site for the regulation of bile acid synthesis from cholesterol. Anderson, Kok, and Javitt (1972) have shown that there is an additional pathway in man for the synthesis of bile acids involving the initial hydroxylation of cholesterol at the 26 position to form 26hydroxycholesterol. This pathway appears to form chenodeoxycholic acid preferentially over cholic acid. The quantitative contribution of this pathway to bile acid synthesis has not yet been fully assessed in man. There are several possible explanations for the observed differences between cholic and chenodeoxycholic acid synthesis in cirrhotic patients. The major pathway for cholic acid synthesis could be blocked by a deficiency of one or more enzymes regulating the synthesis of the 3-keto, 7 alpha, 12 alpha-dihydroxy cholic acid intermediate from cholesterol. If the first hydroxylation step from cholesterol ( 7 alpha-hydroxycholesterol) is depressed, chenodeoxycholic acid synthesis should also be markedly reduced unless chenodeoxycholic acid is synthesized via the reported (Anderson et al, 1972) alternative 26-hydroxycholesterol pathway. Further studies are needed to delineate the site of the impairment in cholic acid synthesis in patients with cirrhosis.

Patients with cirrhosis also exhibit other abnormalities in the metabolism of the bile acids. Deoxycholic acid is virtually absent from the bile of patients with advanced cirrhosis (Vlahcevic, Buhac, Bell, and Swell, 1970). However, as shown in the present report, patients with mild cirrhosis also have a significant decrease in the percentage of biliary deoxycholic acid. These observations suggest that with the advancement of liver disease there is a progressive decrease in biliary deoxycholic acid. These alterations in secondary bile acid metabolism may be due to the impaired colonic absorption of deoxycholic acid or due to the presence of abnormal bacterial flora in the colon. The presence of abnormal bacterial flora in the colon could result in an impaired conversion of cholic to deoxycholic acid. Changes in the conversion of cholic to deoxycholic acid could also account for the prolonged half-life of cholic acid found in patients with advanced cirrhosis. Because of the lack of formation of deoxycholic acid, the cholic acid upon leaving the terminal ileum may be reabsorbed in the colon to a considerable extent. In the normal subject, minimal reabsorption of cholic acid in the colon takes place since almost all of the cholic acid is converted to secondary bile acids. Alternatively, patients with advanced cirrhosis may have fewer enterohepatic cycles as a result of cholestasis and/or impaired gallbladder contractibility (Turnberg and Grahame, 1970). However, if this were the case the turnover rates of both primary bile acids should be similarly affected in these patients. The data of the present and previous study (Vlahcevic et al, 1972) consistently show no significant change in chenodeoxycholic acid turnover rate in patients with cirrhosis. Further studies are needed to clarify the mechanism responsible for the observed abnormality of deoxycholic acid metabolism in cirrhosis.

There was also a significant correlation between cholic acid turnover rate and the advancement of liver disease. Cholic acid turnover rate does not markedly change until the stage of advanced cirrhosis is reached. The decreased turnover rate of cholic acid during this late stage of cirrhosis probably partially compensates for the continued decrease in cholic acid synthesis. Because of these conditions the cholic acid pool did not show any additional decrease beyond the mild stage of cirrhosis.

Because of the marked decrease in cholic acid synthesis, patients with cirrhosis were found to have an increase in the percentage of chenodeoxycholic acid. A significant change in the ratio of biliary trihydroxy to dihydroxy bile acids was not observed in patients with cirrhosis. The failure to observe a significant change in the ratio can probably be attributed to alterations in both cholic and deoxycholic acid metabolism. Although the metabolism of chenodeoxycholic acid in cirrhosis is relatively unaffected, the changes in deoxycholic acid are sufficient to negate any changes in the ratio of trihydroxy to dihydroxy bile acid. Carey (1958) showed that the ratio of trihydroxy to dihydroxy bile acids in plasma was significantly decreased in patients with liver disease. The difference between the observed bile acid ratios in the bile and plasma raise the possibility that the blood and biliary bile acid composition may be different in patients with cirrhosis due to compartmentalization of the bile acid pools.

\section{References}

Anderson, K. E., Kok, E., and Javitt, N. B. (1972). Bile acid synthesis in man. Metabolism of $7 \alpha$-hydroxycholesterol-1 ${ }^{10} \mathrm{C}$ and 26 hydroxycholesterol-3 H. J. clin. Invest., 51, 112-117.

Bergström, S., and Danielsson, H. (1968). Formation and metabolism of bile acids. In Handbook of Physiology, Sect. 6, Alimentary Canal, edited by C. F. Code, Vol. V, pp. 2391-2407. American Physiological Society, Washington, D.C.

Blum, M., and Spritz, N. (1966). The metabolism of intravenously injected isotopic cholic acid in Laennec's cirrhosis. J. clin. Invest., 45, 187-193.

Carey, J. B., Jr. (1958). The serum trihydroxy-dihydroxy bile acid ratio in liver and biliary tract disease. J. clin. Invest., 37, 1494-1503.

Danielsson, H., and Tchen, T. T. (1968). Metabolic Pathways, Vol. 2, 3rd ed., edited by D. M. Greenberg, p. 117. Academic Press, New York 
Folch, J., Lees, M., and Stanley, G. H. S. (1957). A simple method for the isolation and purification of total lipides from animal tissues. J. biol. Chem., 226, 497-509.

Osborn, E. C., Wootton, I. D. P., Da Silva, L. C., and Sherlock, S. (1959). Serum-bile-acid levels in liver disease. Lancet, 2, 1049-1053.

Rudman, D., and Kendall, F. E. (1957). Bile acid content of human serum. I. Serum bile acids in patients with hepatic disease. J. clin. Invest., 36, 530-537.

Shefer, S., Hauser, S., Bekersky, I., and Mosbach, E. H. (1970). Biochemical site of regulation of bile acid biosynthesis in the rat. J. Lipid Res., 11, 404-411.

Shefer, S., Hauser, S., and Mosbach, E. H. (1968). $7 \alpha$-hydroxylation of cholesterol by rat liver microsomes. J. Lipid Res., 9, 328-333.

Snedecor, G. W. (1956). Statistical Methods, 5th ed. Iowa State University Press, Ames, Iowa.

Swell, L. (1968). Gas Chromatography, pp. 97-109. Grune and Stratton, New York.

Theodor, E., Spritz, N., and Sleisenger, M. H. (1968). Metabolism of intravenously injected isotopic cholic acid in viral hepatitis Gastroenterology, 55, 183-190.

Turnberg, L. A., and Grahame, G. (1970). Bile salt secretion in cirrhosis of the liver. Gut, 11, 126-133.

Vlahcevic, Z. R., Buhac, I., Bell, C. C., Jr., and Swell, L. (1970) Abnormal metabolism of secondary bile acids in patients with cirrhosis. Gut, 11, 420-422.

Vlahcevic, Z. R., Buhac, I., Farrar, J. T., Bell, C. C., Jr., and Swell, L. (1971). Bile acid metabolism in patients with cirrhosis. I. Kinetic aspects of cholic acid metabolism. Gastroenterology, 60, $491-498$.

Vlahcevic, Z. R., Juttijudata, P., Bell, C. C., Jr., and Swell, L. (1972). Bile acid metabolism in patients with cirrhosis. II. Cholic and chenodeoxycholic acid metabolism. Gastroenterology, 62, 1174-1181.

Vlahcevic, Z. R., Miller, J. R., Farrar, J. T., and Swell, L. (1971). Kinetics and pool size of primary bile acids in man. Gastroenterology, 61, 85-90. 